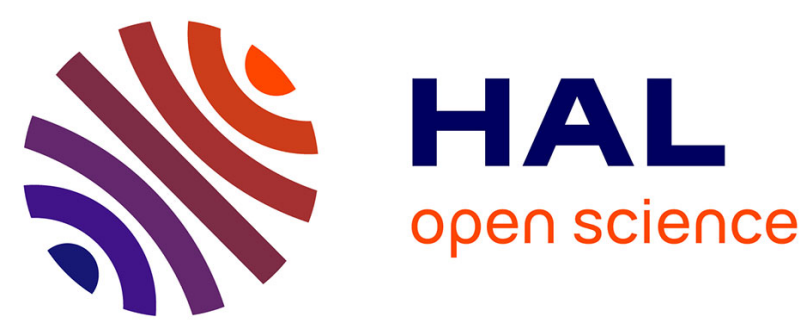

\title{
Presentation and characterization of novel thick-film PZT microactuators.
}

\author{
Vincent Chalvet, Didace Habineza, Micky Rakotondrabe, Cédric Clévy
}

\section{To cite this version:}

Vincent Chalvet, Didace Habineza, Micky Rakotondrabe, Cédric Clévy. Presentation and characterization of novel thick-film PZT microactuators.. Physica B: Condensed Matter, 2016, 486 (1), pp.17-20. 10.1016/j.physb.2015.11.007 . hal-01303483

\section{HAL Id: hal-01303483 \\ https://hal.science/hal-01303483}

Submitted on 18 Apr 2016

HAL is a multi-disciplinary open access archive for the deposit and dissemination of scientific research documents, whether they are published or not. The documents may come from teaching and research institutions in France or abroad, or from public or private research centers.
L'archive ouverte pluridisciplinaire HAL, est destinée au dépôt et à la diffusion de documents scientifiques de niveau recherche, publiés ou non, émanant des établissements d'enseignement et de recherche français ou étrangers, des laboratoires publics ou privés. 


\title{
Presentation and characterization of novel thick-film PZT microactuators
}

\author{
Vincent Chalvet, Didace Habineza, Micky Rakotondrabe, Cédric Clévy
}

\author{
FEMTO-ST Institute, AS2M department, \\ Université de Franche-Comté/CNRS/ENSMM, \\ 24 rue Savary, 25000 Besancon, France. \\ corresponding author: didace.habineza@femto-st.fr
}

\begin{abstract}
We propose in this paper the characterization of a new generation of piezoelectric cantilevers called thick-films piezoelectric actuators. Based on the bonding and thinning process of a bulk PZT layer onto a silicon layer, these cantilevers can provide better static and dynamic performances compared to traditional piezocantilevers, additionally to the small dimensions.
\end{abstract}

Keywords: piezoelectric, cantilever, thinning, hysteresis, creep, dynamics, characterization

\section{Introduction}

PZT (lead, zirconate, titanate) material is widely used in the microworld for the design of highly performant actuators and sensors. Thanks to their high displacement resolution and high bandwidth, pizoelectric actuators are prized for several applications such as in microrobotic domain (cantilevers for microtweezers [1, 2], AFM piezo-scanner [3], etc) or biomedical applications [4]. Despite their high resolution, piezoelectric actuators present several well known nonlinearities, such as hysteresis or creep. Many studies are currently trying to overcome these nonlinearities by using compensation techniques $[5,6,7,8,9,10,11,12,13,14]$, or through feedback control strategies (see $[6,16]$ and references herein).
One of the mainly used piezoactuators is the unimorph cantilever, it is made of one piezoelectric active layer bonded onto a passive elastic layer, resulting in an out of plane displacement when an electric field is applied between the two sides of the piezoelectric layer. Different technologies are used to create PZT piezoactuators. The first one uses bulk PZT layer resulting in thick cantilevers $(>200 \mu \mathrm{m})$ allowing the generation of large bandwidth but with small displacements. In counterpart, another fabrication process consists in the deposition of thin layer of piezoelectric materials (in the range of some micrometers), resulting in thin film cantilevers generating high displacements but with small bandwidth. In [15], we proposed a new fabrication approach resulting in the generation of thick-film piezoactuators, with novel performances both in 
the static and dynamic domains. In fact, the actuators developed with this technology exhibit performances that are taken from the advantages of the classical bulk PZT (large bandwidth) and from those of the thin films (large displacements). Linear assumption and modeling of the actuators have been given for that. In this paper, we deal with the characterization of this novel generation of piezoelectric actuators, for both static and dynamics aspects in order to demonstrate that at the optimal operating range, they also exhibit hysteresis nonlinearities similarly to classical piezoelectric cantilever actuators.

\section{Proposed piezoelectric actuator}

The fabrication process of the piezoelectric actuator, detailed in [15], is based on the gold bonding (at room temperature) of a PZT bulk layer (200 $\mu \mathrm{m}$ thickness) onto a SOI (Silicon On Insulator) wafer. The SOI composed of a $5 \mu \mathrm{m}$ device silicon layer, a 1 $\mu \mathrm{m}$ buried oxide layer (insulator), and a $500 \mu \mathrm{m}$ handle silicon layer. Mechanical thinning and polishing of the PZT layer is then performed. A thin gold film is then deposited on the top surface of the PZT layer, which serves as a top electrode for the cantilever actuation. The gold layer used for the bonding is also used as the bottom electrode. Cantilevers are then sliced into beams with a saw, and the handle layer of the SOI wafer is etched through DRIE (Deep Reactive Ion Etching) process.

The realized unimorph cantilevers had a PZT layer of $h_{p}=25 \mu \mathrm{m}$ thick and a silicon elastic layer of $h_{s}=5 \mu \mathrm{m}$. The length of the cantilevers is $L=4 \mathrm{~mm}$, and the width $w$ varies from 150 to $750 \mu m$ (Figure 1).

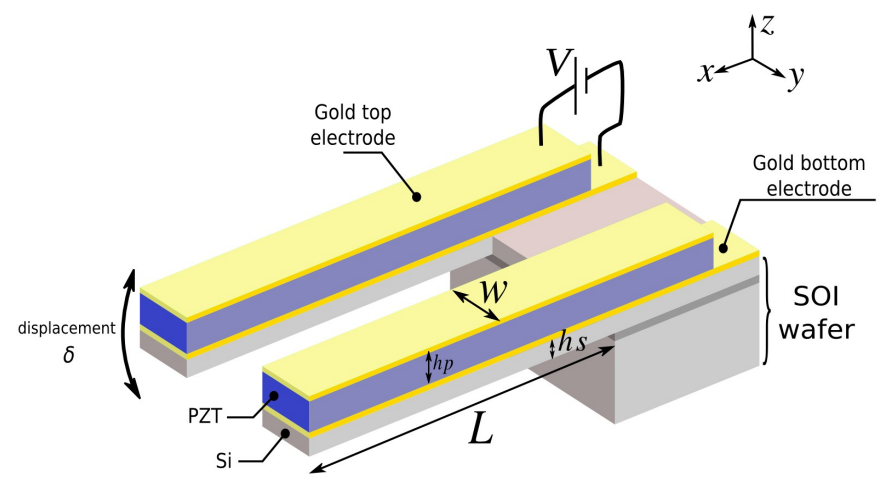

(a) Design of the cantilever.

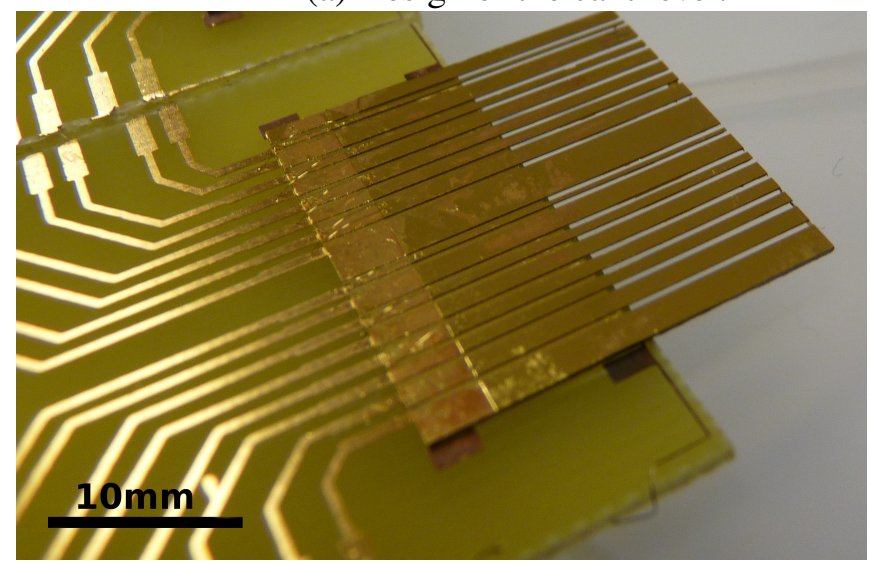

(b) Photo of a set of cantilevers.

Figure 1: Thick-film PZT unimorph cantilever.

\section{Characterization of the piezoelectric actuator}

In the sequel, we use a piezoelectric cantilever actuator of $150 \mu \mathrm{m}$ of width. The characterization setup is composed of:

- the piezoelectric actuator,

- an optical sensor (LC2420 from Keyence companyn) capable of measuring the deflection of the cantilever (displacement) with a resolution of tens of nanometer and bandwidth in excess of $5 \mathrm{kHz}$, 
- and a computer and a dSPACE board used to generate the input voltage and to acquire the measurement. The sampling time is tuned to be $50 \mu \mathrm{s}$.

\subsection{Hysteresis characterization}

In [15], the modeling used to estimate the performances of the actuator was linear. Here, we provide deeper characterization of the actuators which demonstrate that they are nonlinear when increasing the operating range. First, a sine input voltage of amplitude $10 \mathrm{~V}$ is applied to the cantilever actuator used for the experiment. The frequency is chosen to be low relative to the resonant frequency in order to avoid the phase-lag effect and thus to avoid a distorted curve. However, the frequency should not be too low in order to avoid the creep effect which is another nonlinearity found at very low frequency or very low rate [16]. In this case, we choose $0.1 \mathrm{~Hz}$ which is sufficiently low face to the first resonant frequency of the cantilever and sufficiently high relative to the creep frequency domain. Figure 2 depicts the output displacement obtained from the actuator versus the input voltage. As depicted, the actuator strongly exhibit hysteresis whose amplitude exceeds $h / H \approx 14 \%$. We can also see that the gain obtained with the novel actuator is in excess of $3.7 \mu \mathrm{m} / \mathrm{V}$ which is much larger than that of traditional piezoelectric cantilever actuators based on PZT. The gain of these latters are generally less than $1.5 \mu \mathrm{m} / \mathrm{V}$ [16].

To go further on the characterization of the gain of the novel actuator, we apply higher amplitude than $10 \mathrm{~V}$ for the input voltage. Figure 3 depicts the gain which corresponds to the ratio between the amplitude of the output displacement and the amplitude of the input voltage. In the same figure, we also plot the linear model that is used to estimate the displacement in [15]. As we can observe, the gain increases substantially with the input voltage amplitude. Furthermore, the static performance of the actuator is underestimated with the linear model. These experimental characterization results highlight the static performances of the novel actuator.

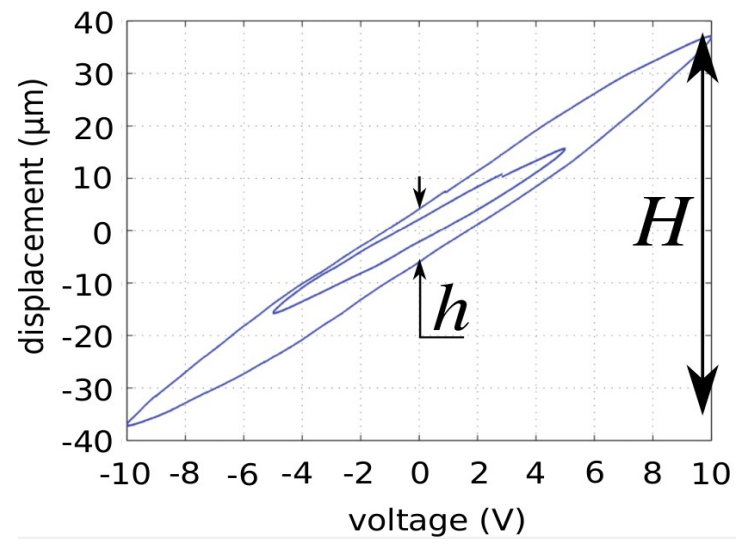

Figure 2: Experimental characterization of the hysteresis nonlinearity.

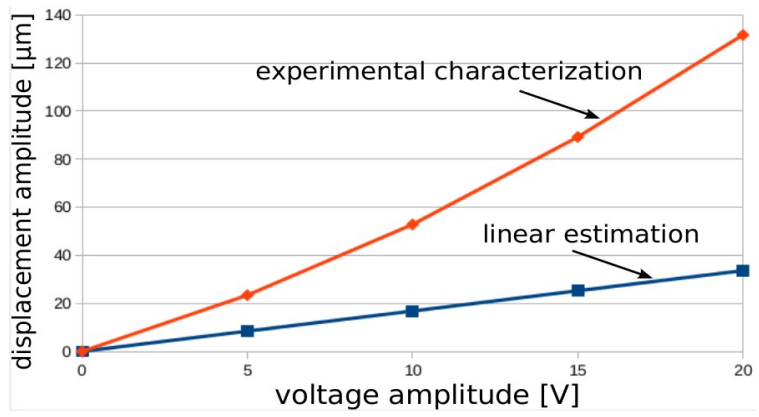

Figure 3: Experimental characterization of the gain of the actuator. 


\subsection{Creep characterization}

Classical piezoelectric cantilever actuators are also known to exhibit creep nonlinearity [16]. The creep is a nonlinear phenomenon observed at very low frequency or very low rate input voltage. To characterize or to model a creep, the most employed procedure consists in applying a step input voltage and observing the output response for a long period duration. Here, a step input voltage of $10 \mathrm{~V}$ amplitude is applied. Figure 4 depicts the results which show a creep of the actuator up to $c / C \approx$ $70 \%$ when observed during 10 minutes. As a conclusion, similarly to the hysteresis, it is shown that the novel actuators exhibit nonlinear phenomenon and the linear model as utilized in [15] is not sufficient to estimate their performances.

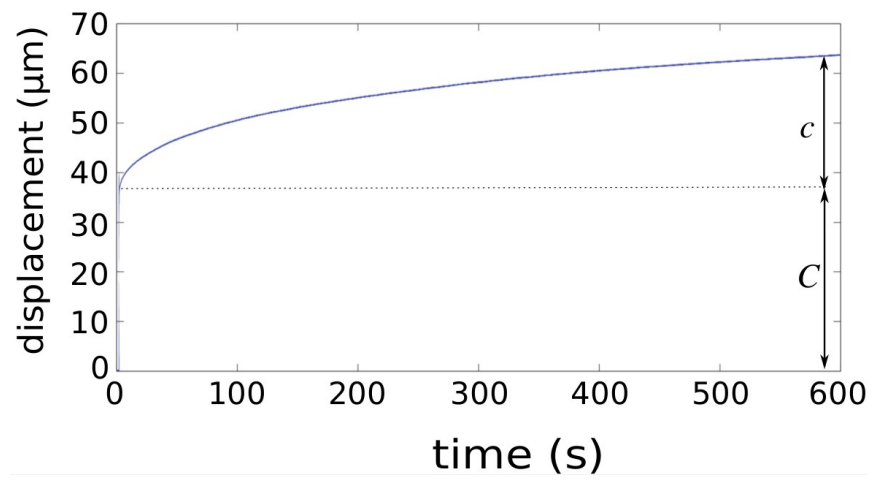

Figure 4: Experimental characterization of the creep nonlinearity.

\subsection{Dynamic characterization}

Here, we characterize the dynamic property of the actuator. For that, additionally to the experimental materials listed above, we use a SR785 spectrum analyzer (from Stanford Research Systems company). A swept sine input voltage of frequency ranging between $0.1 \mathrm{~Hz}$ and $2 \mathrm{kHz}$ is generated thanks to the spectrum analyzer and the bode diagram. Figure 5 depicts the resulting frequency response of the actuator. It shows that the first resonant frequency of the actuator is around $1100 \mathrm{~Hz}$. This is almost twice more than classical piezoelectric cantilever actuators, see for instance in the actuators in [16] which exhibit a first resonant frequency less than $600 \mathrm{~Hz}$.
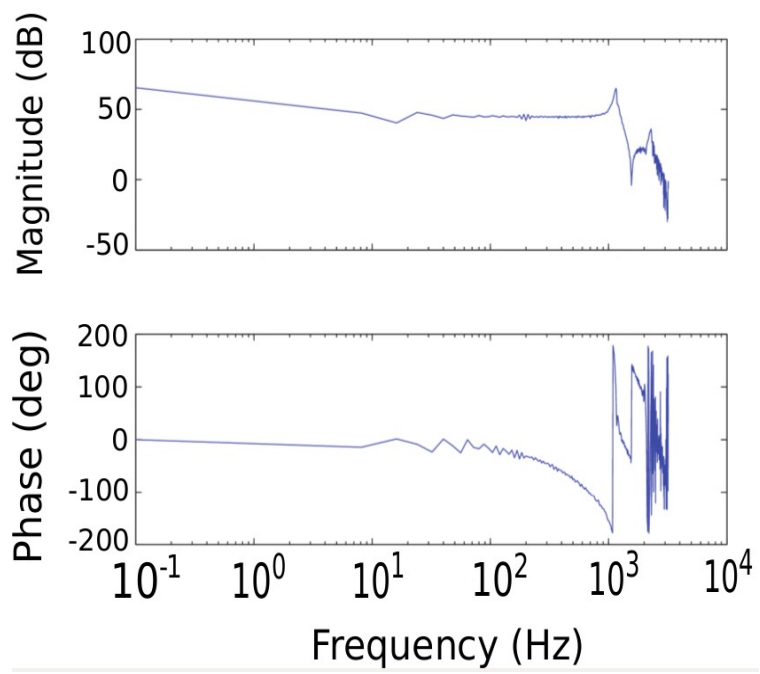

Figure 5: Frequency response of the actuator.

Another way to characterize the dynamic behavior of the actuator is to excite it with a brusque input voltage. A step input voltage of $10 \mathrm{~V}$ amplitude is therefore applied. The step response is depicted in Figure 6 which shows a badly oscillating behavior of the actuator. This behavior is also observed in classical piezoelectric cantilever actuator [16] and is principally due to two reasons: i) the cantilever structure, ii) and the high stiffness of the PZT piezoelectric material. 


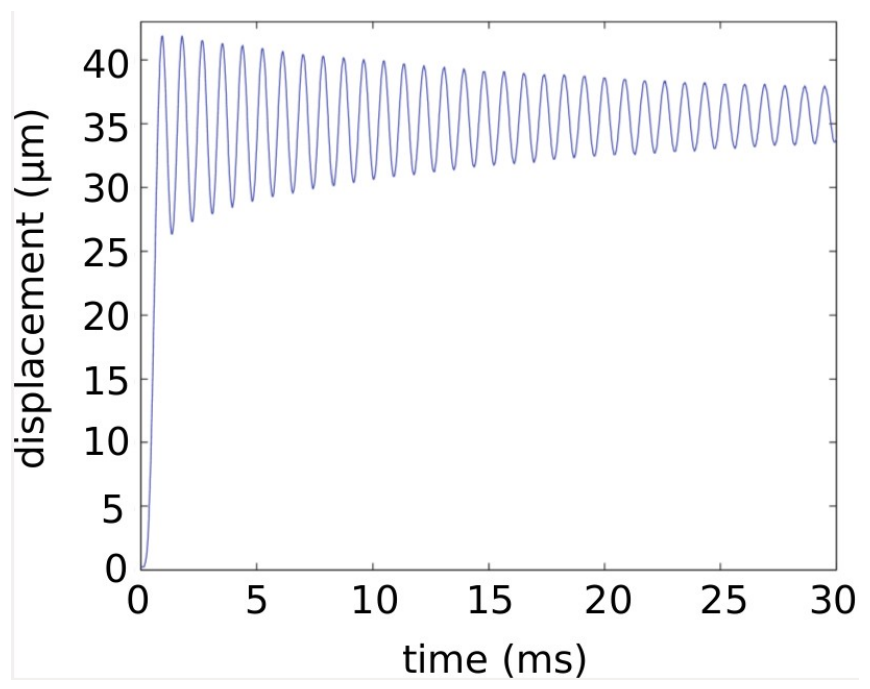

Figure 6: Step response of the actuator.

\section{Conclusion}

This paper dealt with the static and dynamic characterization of a novel piezoelectric cantilever actuator. Along the paper, it is shown that the actuator exhibit much larger gain (in excess of $3.7 \mu \mathrm{m} / \mathrm{V}$ ) and higher dynamics (first resonant frequency $1100 \mathrm{~Hz}$ ) than in classical piezoelectric PZT cantilever actuators. During the characterization, it is also shown that the classical properties, i.e. hysteresis and creep nonlinearities and badly damped oscillations, of piezoelectric actuators are found in this novel generation of actuators.

\section{Aknowledgments}

This work is supported by the national ANR-JCJC C- MUMS-project (National young investigator project ANR-12- JS03007.01: Control of Multivariable Piezoelectric Microsystems with Minimization of Sensors). This work has been supported by the Labex ACTION project (contract "ANR-11-LABX-01-01").

\section{References}

[1] M. Rakotondrabe, I. A. Ivan, Development and force/position control of a new hybrid thermopiezoelectric microgripper dedicated to micromanipulation tasks', IEEE Transactions on Automation Science and Engineering, 2011, Vol. 8, No 4, pp. 824-834.

[2] J. Agnus, N. Chaillet, C. $\mathrm{Cl}^{\prime}$ evy, S. Dembl, M. Gauthier, Y. Haddab, G. Laurent, P. Lutz, N. Piat, K. Rabenorosoa, M. Rakotondrabe and B. Tamadazte, 'Robotic Microassembly and micromanipulation at FEMTO- ST', Journal of Micro-Bio Robotics (JMBR), 2013, Vol. 8, Issue 2, pp. 91-106.

[3] Y. Zhang, Y. Fang, X. Zhou, X. Dong, 'Imagebased hysteresis modeling and compensation for an afm piezo-scanner', Asian Journal of Control, 2009, Vol. 2, No 11, pp. 16-174.

[4] S. Lescano, D. Zlatanov, M. Rakotondrabe, N. Andreff,' Kinematic analysis of a meso-scale parallel robot for laser phonomicrosurgery', in: Interdisciplinary Applications of Kinematics, Springer, 2015, pp. 127135.

[5] M. Rakotondrabe, 'Classical Prandtl-Ishlinskii modeling and inverse multiplicative structure to compensate hysteresis in piezoactuators', ACC, (American Control Conference), June 2012, Montreal, QC, pp.1646- 1651.

[6] S. Devasia, E. E. Eleftheriou, R. Moheimani, 'A survey of control issues in nanopositioning' IEEE Transactions on Control System Technology, 2007, Vol.15, No 15, pp. 802-823.

[7] D. Croft, G. Shed and S. Devasia, 'Creep, hysteresis and vibration compensation for piezoactuators: atomic force microscopy application', ASME Journal of Dynamic Systems, Measurement and Control, 2001, Vol. 123, No 1, pp. 35-43.

[8] M. Rakotondrabe, 'Bouc-Wen modeling and inverse multiplicative structure to compensate 
hysteresis nonlinearity in piezoelectric actuators', IEEE Transactions on Automation Science and Engineering, 2011, Vol.8, No 2, pp. 428-431.

[9] D. Habineza, M. Rakotondrabe and Y. Le Gorrec, 'Bouc-Wen Modeling and Feedforward Control of multivariable Hysteresis in Piezoelectric Systems: Application to a 3-DoF Piezotube scanner', IEEE Transactions on Control Systems Technology, 2015, Vol. 23, Issue 5, pp. 1797-1806. [10] S. Bashash and N. Jalili, 'A Polynomial-Based Linear Mapping Strategy for Feedforward Compensation of Hysteresis in Piezoelectric Actuators', ASME Journal of Dynamic Systems, Measurement and Control, 2008, Vol.130, No 3, p. 031008.

[11] K. Kyle Eddy, 'Actuator bias prediction using lookup-table hysteresis modeling', US Patent08/846545, February 1999.

[12] A. Dubra and J. Massa and C.1 Paterson, 'Preisach classical and nonlinear modeling of hysteresis in piezoceramic deformable mirrors',
Optics Express, 2005, Vol.13, No 22, pp. 90629070.

[13] Ram Venkataraman Iyer, Xiaobo Tan and P. S. Krishnaprasad, 'Approximate Inversion of the Preisach Hysteresis Operator With Application to Control of Smart Actuators', IEEE Transactions on Automatic Control, 2005, Vol.50, No 6, pp. 798810.

[14] D. Hughes and J. T. Wen, 'Preisach modeling and compensation for smart material hysteresis,' Active Materials and Smart Structures, 1994, Vol. 2427, pp. 50-64.

[15] A. Bienaim' e, V. Chalvet, C. $\mathrm{Cl}^{\prime}$ evy, L. Manuel-Gauthier, T. Baron and M. Rakotondrabe, 'Static / dynamic trade-off performance of PZT thickfilm micro-actuators', IOP - Journal of Micromechanics and Microengineering (JMM), 2015, Vol. 25, No 7, p. 075017.

[16] Micky Rakotondrabe, Smart materials-based actuators at the micro/nano-scale: characterization, control and applications, edited book, Springer Verlag, New York, ISBN 978-1-4614-6683-3, 2013. 